\title{
Dampak Interaksi Model Kepemimpinan Dan Budaya Organisasi Terhadap Kinerja Karyawan
}

\author{
Rahmat Laan \\ Burhanudin Gesi
}

\section{Program Studi Manajemen Fakultas Ekonomi Universitas Muahmmadiyah Kupang E-mail : rahmatlaan@yahoo.co.id, burhangesi@gmail.com}

\begin{abstract}
ABSTRAK
Penelitian ini bertujuan (1) Untuk mengetahui model kepemimpinan yang yang lebih menonjol di PT ASDP Cabang Kupang, (2) Untuk mengetahui jenis budaya yang lebih menonjol di PT ASDP Cabang Kupang, (3) Untuk mengetahui dampak kepemimpinan transaksional dan transformasional terhadap kineja pegawai PT ASDP Cabang Kupang, (4) Untuk mengetahui dampak budaya birokratik, inovatif, dan suportif terhadap kinerja pegawai PT ASDP Cabang Kupang, (5) Untuk mengetahui dampak interaksi kepemimpinan transformasional dengan budaya birokratik terhadap kinerja pegawai PT ASDP Cabang Kupang, (6) Untuk mengetahui dampak interaksi kepemimpinan transaksional dengan budaya inovatif terhadap kinerja pegawai PT ASDP Cabang Kupang, (7) Untuk mengetahui dampak interaksi kepemimpinan transaksional dengan budaya suportif terhadap kinerja pegawai PT ASDP Cabang Kupang. Sampel ditentukan dengan menggunakan teknik klaster random sampling (sampling acak berklaster) sebanyak 100 orang. Instrumen utama yang digunakan dalam mengumpulkan data lapangan adalah angket. Dari 100 kuesioner, yang layak dianalisis sebanyak 95 angket. Data dianalisis dengan teknik regresi berganda. Hasil penelitian menunjukkan (1) Model kepemimpinan yang lebih menonjol di PT ASDP Cabang Kupang adalah kepemimpinan transaksional, (2) Jenis budaya organisasi yang lebih menonjol di PT ASDP Cabang Kupang adalah budaya suportif, (3) Model kepemimpinan transaksional dan transformasional secara bersamasama berpengaruh signifikan terhadap kierja karyawan di PT ASDP Cabang Kupang. Secara parsial kepemimpinan transformasional berpengaruh signifikan terhadap kinerja karyawan di PT ASDP Cabang Kupang, tetapi kepemimpinan transaksional tidak berpengaruh signifikan terhadap kierja karyawan di PT ASDP Cabang Kupang, (4) budaya birokratik, inovatif dan suportif secara simultan berpengaruh signifikan terhadap kinerja karyawan PT ASDP Cabang Kupang. Secara parsial budaya birokratik dan suportif berpengaruh signifikan terhadap kinerja karyawan PT ASDP Cabang Kupang, tetapi budaya inovatif tidak berpengaruh signifikan terhadap kinerja karyawan PT ASDP Cabang Kupang, (5) Interaksi kepemimpinan transformasional dengan budaya birokratik berpengaruh signifikan terhadap kinerja karyawan PT ASDP Cabang Kupang, (6) Interaksi kepemimpinan transaksional dengan budaya inovatif tidak berpengaruh signifikan terhadap kinerja karyawan PT ASDP Cabang Kupang, dan (7) Interaksi kepemimpinan transaksional dengan budaya suportif tidak berpengaruh signifikan terhadap kinerja karyawan PT ASDP Cabang Kupang.
\end{abstract}

Kata Kunci : Kepemimpinan, Budaya Organisasi, Kinerja 


\section{PENDAHULUAN}

Kinerja pegawai adalah perkara penting baik bagi organisasi maupun individu pegawai. Bagi individu, melakukan dan menyelesaikan tugas pada tingkat tinggi dapat menjadi sumber kepuasan, motivasi, dan kebanggaan. Bekerja dengan kinerja yang rendah, mungkin akan tidak memuaskan atau bahkan sebagai indikasi kegagalan pribadi. Meskipun mungkin ada pengecualian, berkinerja tinggi lebih mudah dipromosikan dalam suatu organisasi dan umumnya memiliki peluang karier yang lebih baik dari pada berkinerja rendah. Sedangkan organisasi lebih mengutamakan orang yang berkinerja tinggi dalam melakukan tugas-tugas pelayanan untuk mencapai visi, misi dan tujuan yang ditetapkan.

Namun demikian apa yang diinginkan oleh organisasi tidak selalu terjadi dalam kenyataan. Hal ini dialami oleh PT Angkutan Sungai Danau dan Penyeberengan (ASDP) Indoensia Ferry Cabang Kupang. Indikasinya terlihat dari masih rendahnya kualitas pelayanan yang diberikan oleh perusahaan tersebut kepada masyarakat pengguna jasa penyeberangan, seperti pelayanan yang tidak ramah, keberangkatan kapal yang terkadang tidak tepat waktu, pelayanan yang terkesan diskriminatif dan sebagainya yang berujung pada rendahnya kinerja organisasi secara keseluruhan.

Banyak faktor yang mempengaruhi kinerja pegawai. Studi Kilmann (1996) menemukan tendensi bahwa untuk menciptakan dan mempertahankan keberhasilan organisasi perlu diperhatikan lima faktor : (1) budaya organisasi, (2) keterampilan (gaya) kepemimpinan, (3) pengembangan tim, (4) strategi-struktur, (5) sistem imbalan. Studi Pfeffer (1996) mendeteksi bahwa sumber daya manusia, budaya organisasi dan gaya kepemimpinan, kini semakin penting, sebagai penyumbang kinerja.

Penelitian ini akan mengkaji gaya kepemimpinan dan budaya organisasi (Kilmann, 1996; Pfeffer, 1996) sebagai determinan kinerja pegawai PT ASDP Indonesia Ferry Cabang Kupang. Kepemimpinan dipilih karena adanya harapan bahwa organisasi ini seharusnya memiliki kepemimpinan yang mampu meningkatkan kesadara bawahan terhadap nilai, hasil usaha, pentingnya penyelesaian tugas, makna bekerja, tujuan moral kerja, dan memperhatikan kebutuhan pegawai melalui kewenangan dan pengaruh yang dimilikinya untuk bersama-sama mencapai tujuan organisasi. Sedangkan budaya organisasi yang diharapkan adalah budaya yang cocok untuk lingkungan kerja kreatif dan inovatif, serta budaya yang menghendaki kerja sama dan saling mendukung antara berbagai komponen dalam organisasi. 
Di sisi lain masih tampak bahwa kepemimpinan di perusahaan ini sering menuntut loyalitas total dari anak-buahnya, mengembangkan sistem nepotisme, berorientasi pada politik kekuasaan, tidak ada pembagian kewenangan dalam pengambilan keputusan, komunikasi top-down, tercipta formalitas hubungan antara atasan dan bawahan yang berlebihan, dan lain-lain. Dari aspek budaya organisasi, tampak organisasi dikelola secara hirarkis, disusun secara birokratis, memiliki monopoli, menerapkan spesifikasi-spesifikasi yang sangat detail, unit-unit fungsional, aturan-aturan prosedural dan uraian tugas untuk menentukan apa yang harus dilakukan pegawai. Hal ini menimbulkan budaya yang membuat pegawai sangat reaktif dalam pengertian negatif, tidak mandiri, dan takut mengambil inisiatif sehingga pada gilirannya membentuk budaya saling menyalahkan, rasa takut kepada atasan dan menimbulkan sikap defensif.

Kepemimpinan dan budaya organisasi tersebut, tidak saja menyebabkan rendahnya kinerja pegawai,tetapi juga sangat tidak kondusif terhadap harapan akan sebuah kepemimpinan dan budaya organisasi yang mampu merespon berbagai tuntutan perubahan dan dinamika masyarakat konsumen yang bergerak cepat.

Pertanyaannya, apakah PT ASDP Indonesia Ferry sudah memiliki kepemimpinan dan budaya organisasi yang diharapkan tersebut. Untuk itu penelitian ini akan memotretnya dengan konsep kepemimpinan transaksional dan transformasional (Burns, 1978), dan konsep budaya birokratik, inovatif dan suportif (Wallach, 1983).

Sejumlah studi memperlihatkan bahwa model kepemimpinan dari Burns dan dimensi budaya organisasi dari Wallach mempunyai implikasi yang berbeda bagi kinerja pegawai. Studi Pradeep dan Prabhu (2011) menyimpulkan bahwa korelasi kepemimpinan transaksional dengan kinerja karyawan lebih rendah dari kepemimpinan transformasional. Studi Webb (2007) dan Trottier, dkk (2008) menemukan bahwa motivasi dan kepuasan kerja pegawai lebih besar bila dibawah kepemimpinan transformsional dibandingkan kepemimpinan transaksional. Studi Odom, dkk (1990) menunjukkan bahwa lingkungan kerja birokratik tidak akan memperbaiki atau bahkan mengganggu komitmen, kepuasan dan kohesi kelompok kerja dari para pegawai. Tetapi sikap dan perilaku pegawai meningkat oleh karakterisitik yang ditunjukkan oleh budaya inovatif dan budaya suportif.

Dari implikasi tersebut dapat dirumuskan beberapa kemungkinan proposisi : (1) Jika model kepemimpinan transformasional dikombinasikan dengan budaya birokratik maka akan meningkatkan kinerja pegawai; (2) Jika model kepemimpinan transaksional dikombinasikan dengan budaya inovatif akan meningkatkan kinerja pegawai; (3) Jika 
model kepemimpinan transaksional dikombinasikan dengan budaya suportif akan menigkatkan kinerja pegawai.

\section{TINJAUAN PUSTAKA}

\section{Kepemimpinan Transaksional}

Kepemimpinan transaksional adalah tipe kepemimpinan yang secara umum digunakan dalam ilmu perilaku. Pelopor kepemimpinan transaksional adalah Burns (1978) yang menjelaskan kepemimpinan transaksional sebagai hubungan pertukaran antara pemimpin dan pengikut. Fokus utama pemimpin transaksional adalah penjelasan peran bawahan dan pemimpin untuk mengetahui apa yang dibutuhkan pegawai dalam mencapai tujuan organisasi. Bass dan Stogdills (1990) dan Avolio, dkk (2004) mengemukakan atribut kepemimpinan transaksional dalam dua cara : pertama, contingent rewards dan yang lain management by exception. Hellriegel dan Slocum (2006) menjelaskan bahwa kepemimpinan transaksional berdasarkan pada tiga komponen utama : contingent rewards, active management by exception, passive management by exception. Pada contingent rewards pemimpin transaksional menyediakan reward untuk menukar pencapaian target dan target ini ditetapakan atas dasar jangka pendek dan dapat diukur.

Pada active management by exception pemimpin memonitor kinerja bawahan dan mengeliminasi penyimpangan bawahan dari tujuan. Pada passive management by exception pemimpin transaksional menghubungkan persoalan pegawai apabila bawahan memberikan kinerja yang tidak dapat diterima. Kepemimpinan transaksional sebuah model kepemimpinan yang merubah interaksi antar pengikut pada rewards dan peningkatan produktivitas. Secara singkat bahwa kepemimpinan transaksional menyediakan benefit untuk pencapaian tujuan sedangkan hukuman bila tidak mencapai target.

\section{Kepemimpinan transformasional}

Kepemimpinan transformasional dapat dilacak pada konteks evaluasi selama tahun 1978 dengan pengembangan teori kepemimpinan transformasional dan diperkaya dengan perbedaan aspek selama perjalanan waktu. Burns (1978) menerbitkan buku tentang kepemimpinan yang membedakan kepemimpinan transformasional dengan kepemimpinan tradisional. Teori Burns tentang kepemimpinan transformasional menjelaskan bahwa pemimpin memiliki kualitas moral yang lebih dan pemimpin memperhatikan kepentingan yang lebih besar di atas kepentingan kelompok.Teori kepemimpinan Burns diperkaya oleh 
Bass (1985) dengan memperkenalkan kepemimpinan transformasional dalam konteks teori formal, model dan faktor-faktor pengukuran.

Tichi dan Devanna (1986) menyajikan karakteritik yang berkaitan dengan estimasi kepemimpinan transformasional meliputi kualitas, keberanian, keterbukaan, nilai-nilai, pembelajaran dan kemampuan visioner. Kemampuan transformasional ini memiliki atribut spesifik, sedangkan Avolio dan Bass (1994) megklasifikasi skiil kepemimpinan dalam 4 I mencakup : idealized influence, inspirational motivation, intelektual stimulation, dan individualized consideration. Teori kepemimpinan transformasional mengemukakan kekuasaan pemimpin memotivasi bawahan untuk mencapai lebih dari yang direncanakan oleh bawahan (Krishnan, 2004). Bass dan Riggio (2006), Baldoni (2005) dan peneliti lain setuju bahwa kepemimpinan transformasional mempunyai empat elemen mencakup idealized influence, inspirational motivation, intelektual stimulation, dan individualized consideration. Kemampuan manajerial adalah kemampuan lain dari kepemimpinan tranfoemasional yang juga mendasar bagi pemimpin. Kepemimpinan transformasional tidak dapat secara efektif diimplementasikan tanpa beberapa atribut utama kepemimpinan seperti : creatifitas, orientasi tim, dan penghargaan, wewenang pengajaran, tanggung jawab dan pengakuan (Perry, 1996). Kualitas elemen-elemen kepemimpinan transformasional adalah dasar bagi keberhasilan manajemen (Simic, 1998). Perilaku pemimpin menghadapi pegawai atau bahwahan harus menunjukkan rasa hormat, kepercayaan dan keyakinan. Pemimpin membangun rasa hormat bagi yang lain, menunjukkan rasa tanggung jawab, melestarikan pemberian penghargaan dan menghilangkan semua kendala sebagai jalan bagi kemajuan pegawai.

\section{Budaya Organisasi}

Gagasan budaya organisasi diidentifikasi sebagai salah satu aspek utama dari perilaku organisasi, berguna untuk memahami bagaimana organisasi bekerja (Kristof, 1996) dan bagaimana seorang pekerja dapat menjadi baik khusunya dalam organisasi (O'Reilly, 1989). Pemimpin mengapresiasi budaya organisasi postif yang memperkuat fundamental kepercayaan dan perilaku, pemimpin tidak menganggap baik bagi perusahaan jika memperlemah nilai dan kegiantan. Sebalikya budaya negatif menjadi racun bagi kehidupan organisasi dan mengahambat potensi pertumbuhan (Kaufman, 2002). Literatur tentang budaya organisasi mengajukan jenis budaya yang berbeda. Martin (1992) mengajukan tiga 
perspektif : integrasi, diferensiasi, dan fragmentasi. Dengan cara yang sama Wallach (1983) mengemukakan tiga jenis budaya organisasi : birokratik, inovatif dan suportif.

$\begin{array}{ccccc}\text { Budayabirokratik } & \text { memiliki garistanggung jawab dan wewenang yang } \\ \text { jelas;bekerjasangat } & \text { terorganisir, } & \text { diadakan } & \text { pembagian/penggolongan, } & \text { dan }\end{array}$
sistematis.Informasi dan wewenang mengikutihirarki danberbasispada kontroldan kekuasaan.Budayainovatif menunjukkan lingkungan kerjakreatifdi manatantangan dan pengambilan risikoadalah norma.Stimulasiadalahteman setiapegawai. Budaya suportif menunjukkan lingkungan kerja yang ramah, dan pegawai cenderung bersikap adil dan saling membantu satu sama lain dan bagi organisasi. Keterbukaan, lingkungan yang harmonis dianjurkan dan nilai-nilai 'kekeluargaan' dikembangkan. Organisasi mendukung karyawannya, mengungkapkan dukungan melalui sikap yang membangun seperti : saling percaya, adil, aman, membanggakan, ramah, berorientasi hubungan, kolaboratif/kerja sama, dan sebagai pemberi kebebasan pribadi. Organisasi berusaha untuk mendasarkan gayanya pada prinsip humanistik atau berorietasi pegawai. Wallach mengemukakan pentingnya kesesuaian yang tepat atau kecocokan antara organisasi dan kebutuhan dan pribadi pegawainya. Dia mengajukan hipotesis bahwa budaya organisasi yang sesuai dengan kepribadian dan kebutuhan seorang pegawai, lebih memungkinkan pegawai akan tetap pada organisasi dan bekerja dengan baik.

\section{Kinerja}

Sarmiento, dkk (2007) mengemukakan bahwa kinerja kerja sering merupakan hasil dari paling tidak dua aspek : kemampuan dan skill (kebiasaan dan belajar) yang dimiliki seorang pegawai dan motivasinya untuk melakukan pekerjaan yang lebih baik. Selain itu, sejumlah penulis percaya bahwa pegawai dapat menolong memperbaiki kinerja bisnis melalui kemampuan mereka untuk menghasilakan ide-ide dan menggunakan ini sebagai dasar bagi produk, jasa, dan proses kerja baru yang lebih baik. Dengan kata lain, banyak praktisi dan akademisi mendukung pandangan bahwa inovasi pegawai membantu mencapai keberhasilan organisasi (Axtell dkk, 2000, Smith, 2002)

Kinerja menurut Campbell et al (1993) adalah apa yang organisasi harapkan untuk dilakukan oleh seseorang, dan ia melakukannya dengan baik. Jadi, kinerja tidak didefinisikan oleh tindakan itu sendiri tetapi oleh proses pertimbangan dan evaluatif. Sedangkan Higgins (1984) mengidentifikasi kinerja sebagai hasil kerja yang dapat dicapai oleh seseorang atau sekelompok orang dalam suatu organisasi, sesuai wewenang dan 
tanggung jawab masing-masing dalam rangka mencapai tujuan organisasi secara legal, tidak melanggar hukum dan sesuai moral maupun etika. Dalam konteks pelayanan publik, kinerja pegawai adalah hasil kerja atau prestasi kerja setiap pegawai dalam memberikan pelayanan kepada masayarakat sesuai dengan tugas, fungsi dan tanggung jawabnya dengan tanpa melanggar ketentuan peraturan perundang-undangan yang berlaku.

Untuk mengetahui kinerja seorang pegawai dalam melaksanakan tugas, organisasi melaksanakan apa yang disebut sebagai penilaian kinerja/performance appraisal (Bernardin \& Rusel, 1993; Rivai \& Sagala, 2009). Penilaian kinerja harus memberikan gambaran yang akurat dari kinerja seorang pegawai (Desler, 1997; Rivai \& Sagala, 2009). Untuk itu diperlukan faktor-faktor penentu kinerja seorang pegawai yaitu . kuantitas pekerjaan, kualitas pekerjaan, ketepatan waktu, pengetahuan tentang pekerjaan, keterampilan, kemampuan mengatur pekerjaan, kerja sama, komunikasi, inisiatif dan kreatifitas.(Mondy, Siharplin, Flipo, 1995; Furtwengler, 2002; Bernadin \& Russel, 1993; Rafianto, 1986).

\section{MODEL PENELITIAN}

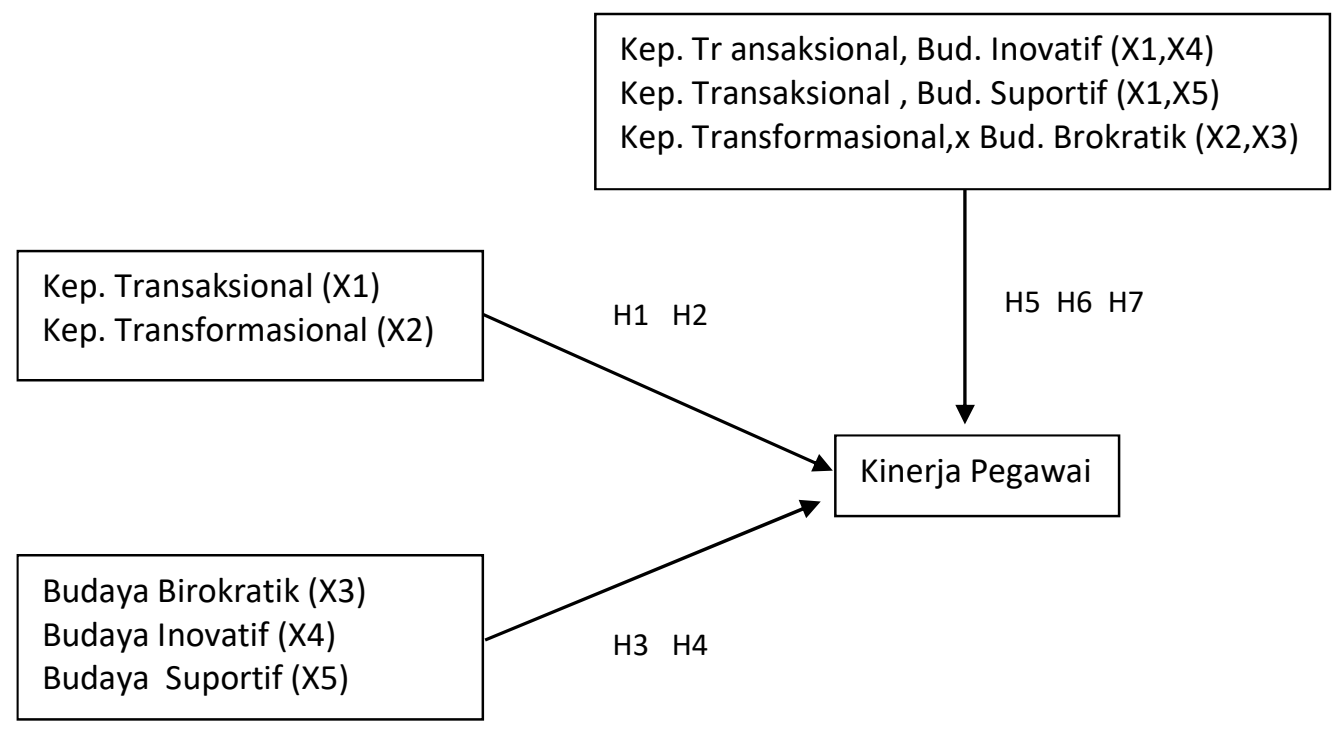

\section{HIPOTESIS}

H1. Kepemimpinan transaksional dan transformasional secara parsial berpengaruh signifikan terhadap kineja pegawai PT ASDP Indonesia Ferry Cabang Kupang. 
H2. Kepemimpinan transaksional dan transformasional secara simultan berpengaruh signifikan terhadap kineja pegawai PT ASDP Indonesia Ferry Cabang Kupang.

H3. Budaya birokratik, inovatif, dan suportif secara parsial berpengaruh signifikan terhadap kinerja pegawai PT ASDP Indonesia Ferry Cabang Kupang.

H4. Budaya birokratik, inovatif, dan suportif secara simultan berpengaruh signifikan terhadap kinerja pegawai PT ASDP Indonesia Ferry Cabang Kupang.

H5. Interaksi kepemimpinan transaksional dengan budaya inovatif berpengaruh signifikan terhadap kinerja pegawai PT ASDP Indonesia Ferry Cabang Kupang.

H6. Interaksi kepemimpinan transaksional dengan budaya suportif beerpengaruh signifikan terhadap kinerja pegawai PT ASDP Indonesia Ferry Cabang Kupang.

H7. Interaksi kepemimpinan transformasional dengan budaya birokratik berpengaruh signifikan terhadap kinerja pegawai PT ASDP Indonesia Ferry Cabang Kupang

\section{METODE}

\section{Populasi dan Sampel}

Populasi penelitian adalah seluruh pegawai PT ASDP Indonesia Ferry Cabang Kupang yang berjumlah 185 orang. Sedangkan sampel ditetapkan secara klaster sesuai dengan bidang kerja yakni kantor, pelabuhan dan kapal, sebagaimana pada tabel 3.1. Teknik penarikan sampel adalah acak sederhana

Tabel 1.

Kerangkan Sampel Penelitian

\begin{tabular}{|c|c|c|c|c|}
\hline No & $\begin{array}{c}\text { Bagian } \\
\text { Pekerjaan }\end{array}$ & Jumlah & $\begin{array}{c}\text { Perhitungan } \\
\text { Sampel }\end{array}$ & Sampel \\
\hline 1 & Kantor & 34 & $34 / 185 \times 100=18,3$ & 18 \\
\hline 2 & Pelabuhan & 13 & $13 / 185 \times 100=7$ & 7 \\
\hline 3 & Kapal & 138 & $138 / 185 \times 100$ & 74 \\
\hline Jumlah & & 185 & & 100 \\
\hline
\end{tabular}

\section{Varibel, Indikator, Instrumen dan Skala}

Variabel dalam penelitian ini terdiri dari variabel bebas : model kepemimpinan transaksional X1), model kepemimpinan transformasional (X2), budaya birokratik (X3), budaya inovatif (X4) dan budaya suportif (X5), varabel terikat : kinerja pegawai PT ASDP Indonesia Ferry Cabang Kupang (Y). Idikator, instrumen dan skala setiap variabel pada tabel berikut : 
Tabel 2.

Variabel, Indikator, Instrumen dan Skala

\begin{tabular}{|c|c|c|c|}
\hline Variabel & Indikator & Instrumen & Skala \\
\hline $\begin{array}{l}\text { Kepemimpinan } \\
\text { Transaksional (X1) }\end{array}$ & $\begin{array}{l}\text { - Imbalan kerja; } \\
\text { - Kontrol aktif; } \\
\text { - Kontrol pasif. }\end{array}$ & MLQ-Form 5X Short & $\begin{array}{l}\text { 1-5 (tidak sama } \\
\text { sekali - sering }\end{array}$ \\
\hline $\begin{array}{l}\text { Kepemimpinan } \\
\text { Transformasional } \\
\text { (X2) }\end{array}$ & $\begin{array}{ll}\text { - } & \text { Pengaruh idel; } \\
\text { - } & \text { Motivasi inspirasi; } \\
\text { - } & \text { Stimulasi intelektual; } \\
\text { - } & \text { Konsiderasi individu. }\end{array}$ & MLQ-Form 5X Short & $\begin{array}{l}\text { 1-5 (tidak sama } \\
\text { sekali - sering }\end{array}$ \\
\hline $\begin{array}{l}\text { Budaya Birokratik } \\
\text { (X3) }\end{array}$ & $\begin{array}{ll}\text { - } & \text { Hirarkis/berjenjang } \\
\text { - } & \text { Procedural } \\
\text { - } & \text { Terstruktur } \\
\text { - } & \text { Tertata } \\
\text { - } & \text { Teratur } \\
\text { - } & \text { Mapan-kokoh/kuat } \\
\text { - } & \text { Bersikap hati-hati } \\
\text { - } & \text { Berorientasi } \\
& \text { kekuasaan }\end{array}$ & $\begin{array}{l}\text { Organizational } \\
\text { Culture Index (OCI) }\end{array}$ & $\begin{array}{l}\text { 1-5 (tidak } \\
\text { menjelaskan } \\
\text { organisasi saya s/d } \\
\text { paling banyak } \\
\text { menjelaskan } \\
\text { organisasi saya }\end{array}$ \\
\hline $\begin{array}{l}\text { Budaya Inovatif } \\
(\mathrm{X} 4)\end{array}$ & $\begin{array}{ll}\text { - } & \text { Mengambil resiko } \\
\text { - } & \text { Kreatif } \\
\text { - } & \text { Berorientasi hasil } \\
\text { - } & \text { Memberi tekanan } \\
\text { - } & \text { Membangkitkan } \\
& \text { semangat } \\
\text { - } & \text { Menawarkan } \\
& \text { tantangan } \\
\text { - } & \text { Giat } \\
\text { - } & \text { Menggerakan. }\end{array}$ & $\begin{array}{l}\text { Organizational } \\
\text { Culture Index (OCI) }\end{array}$ & $\begin{array}{l}\text { 1-5 (tidak } \\
\text { menjelaskan } \\
\text { organisasi saya s/d } \\
\text { paling banyak } \\
\text { menjelaskan } \\
\text { organisasi saya }\end{array}$ \\
\hline $\begin{array}{l}\text { Budaya Suportif } \\
\text { (X5) }\end{array}$ & $\begin{array}{ll}\text { - } & \text { Kolaboratif/kerja sama } \\
\text { - } & \text { Berorientasi hubungan } \\
\text { - } & \text { Membanggakan } \\
\text { - } & \text { Ramah } \\
\text { - } & \text { Pemberi kebebasan } \\
& \text { pribadi } \\
\text { - } & \text { Adil } \\
\text { - } & \text { Terpercaya } \\
\text { - } & \text { Aman }\end{array}$ & $\begin{array}{l}\text { Organizational } \\
\text { Culture Index (OCI) }\end{array}$ & $\begin{array}{l}\text { 1-5 (tidak } \\
\text { menjelaskan } \\
\text { organisasi saya s/d } \\
\text { paling banyak } \\
\text { menjelaskan } \\
\text { organisasi saya }\end{array}$ \\
\hline $\begin{array}{l}\text { Kinerja Pegawai } \\
(\mathrm{Y})\end{array}$ & $\begin{array}{l}\text { - Kuantitas pekerjaan } \\
\text { - Kualitas pekerjaan } \\
\text { - } \text { Ketepatan waktu } \\
\text { - Pengetahuan tentang } \\
\text { pekerjaan } \\
\text { - Keterampilan } \\
\text { - Kemampuan mengatur } \\
\text { pekerjaan } \\
\text { - Kerja sama } \\
\text { - Komunikasi }\end{array}$ & Kuesioner & $\begin{array}{l}\text { 1-5 (sangat tidak } \\
\text { setuju s/d sangat } \\
\text { setuju. }\end{array}$ \\
\hline
\end{tabular}




\section{Analisis Data}

a. Model kepemimpinan dengan kinerja pegawai :

$$
\mathrm{Y}=\mathrm{a}+\mathrm{b}_{1} \mathrm{X}_{1}+\mathrm{b}_{2} \mathrm{X}_{2}+\mathrm{e}
$$

b. Dimensi budaya organisasi dengan kinerja pegawai :

$$
\mathrm{Y}=\mathrm{a}+\mathrm{b}_{3} \mathrm{X}_{3}+\mathrm{b}_{4} \mathrm{X}_{4}+\mathrm{b}_{5} \mathrm{X}_{5}+\mathrm{e}
$$

c. Model interaksi antara model kepemimpinan dengan dimensi budaya organisasi dengan kinerja pegawai

$$
\mathrm{Y}=\mathrm{a}+\mathrm{b}_{1} \mathrm{X}_{1} * \mathrm{X}_{4}+\mathrm{b}_{2} \mathrm{X}_{1} * \mathrm{X}_{5}+\mathrm{b}_{3} \mathrm{X}_{2} * \mathrm{X}_{3}+\mathrm{e}
$$

Dimana :

$\mathrm{Y}=$ Kinerja pegawai

$\mathrm{X}_{1}=$ Kepemimpinan transaksional

$\mathrm{X}_{2}=$ Kepemimpinan transformasional

$\mathrm{X}_{3}=$ Budaya birokratik

$\mathrm{X}_{4}=$ Budaya inovatif

$\mathrm{X}_{5}=$ Budaya suportif

$\mathrm{a}=$ Konstanta

b1, b2, b3, b4, b5 = Koefisien regresi

$\mathrm{e}=$ error term

\section{HASIL PENELITIAN}

\section{Uji Validitas dan Reliabilitas Instrumen}

Sepuluh item pernyataan pada variabel kepemimpinan transaksional terkategori valid. Demikian juga dengan 11 item pernyataan pada kepemimpinan transformasional. Semua item pernyataan pada variabel budaya birokratik, budaya inovatif dan budaya suportif juga berada pada kategori valid. Dari 24 item pernyataan pada variabel kinerja, hanya dua item yang tidak valid, sedangkan 22 sisanya valid (lihat lampiran). Dua item yang tidak valid tidak akan diikutsertakan pada analisis lanjutan. Selanjutnya hasil uji reliabilitas dapat disimak pada table berikut : 
Tabel 3. Hasil Uji Reliabilitas

\begin{tabular}{|l|l|l|l|}
\hline \multicolumn{2}{|c|}{ Variabel Penelitian } & Alpha Cronbach & Ket. \\
\hline \multirow{4}{*}{ Variabel Bebas (X) } & $\begin{array}{l}\text { Kepemimpinan } \\
\text { Transaksional (X1) }\end{array}$ & .753 & Reliabel \\
\cline { 2 - 4 } & $\begin{array}{l}\text { Kepemimpinan } \\
\text { Transformasional (X2) }\end{array}$ & .835 & Reliabel \\
\cline { 2 - 4 } & Budaya Birokratik (X3) & .703 & Reliabel \\
\cline { 2 - 4 } & Budaya Inovatif (X4) & .781 & Reliabel \\
\cline { 2 - 4 } & Budaya Suportif (X5) & .968 & Reliabel \\
\hline Variabel Terikat (Y) & Kinerja Pegawai & .832 & Reliabel \\
\hline
\end{tabular}

Sumber : Data primer, diolah, 2018

Dari tabel di atas tampak bahwa semua variabel memiliki nilai Alpha Cronbach lebih besar dari 0,6. Dengan demikian dapat dikatakan bahwa semua instrumen yang digunakan dalam penelitian ini reliable

\section{Deskripsi Variabel Penelitian}

Model kepemimpinan transaksional oleh para responden dipersepsikan berada pada kategori sedang dengan nilai rata-rata 3,91. Ini berarti bahwa indicator kepemimpinan transaksional yang terdiri dari Imbalan Kerja, Kontrol Aktif, dan Kotrol Pasif kadangkadang diterapkan oleh pemimpin PT ASDP Cabang Kupang.

Model kepemimpinan transformasional dipersespikan oleh para responden berda pada kategori sedangn dengan nilai rata-rata 3,56. Hal ini memberi makna bahwa indicator Pengaruh Ideal (X2.1), Motivasi Inspirasi (X2.2), Stimulasi Intelektual (X2.3), dan Konsiderasi Individu (X2.4) kadang-kadang dilakukan oleh pemimpin PT ASDP Cabang Kupang.

Walaupun kedua model kepemimpinan tersebut diterapkan dalam kategori yang sama yakni sedang, namun dari nilai rata-rata tampak bahwa model kepemimpinan yang lebih menonjol dirasakan oleh para karyawan adalah kepemimpinan transaksional, hal mana nilai rata-rata kepemimpinan transaksional lebih besar dari kepemimpinan transformasional.

Budaya birokratik, dan inovatif dipersepsikan oleh para responden berada pada kategori sedang dengan nilai rata-rata masing-masing 3,82 dan 3,93. Ini berarti bahwa PT ASDP kadang-kadang digambarkan dengan kedua budaya tersebut. Sedangkan budaya suportif dipersepsikan oleh para responden berada pada kategori tinggi dengan nilai ratarata 4,00, yang berarti PT ASDP sering menggambarkan jenis budaya ini. Di lihat dari 
perbandingan nilai rata-rata tampak bahwa PT ASDP memiliki budaya suportif dibandingkan dengan dua jenis budaya yang lain.

Hasil hitung rata-rata indicator dan variabel dapat diliahat pada table berikut :

Tabel 4

Nilai Rerata Indikator dan Variabel

\begin{tabular}{|c|c|c|}
\hline Variabel/Indikator & Mean & Kategori \\
\hline \multicolumn{3}{|l|}{ 1. Kepemimpinan Transaksional (X1) } \\
\hline Imbalan Kerja (X1.1) & 3,96 & $\mathrm{~S}$ \\
\hline Kontrol Aktif (X1.2) & 3,92 & $\mathrm{~S}$ \\
\hline Kotrol Pasif (X1.3) & 3,86 & $\mathrm{~S}$ \\
\hline Rerata Variabel & 3,91 & $\mathrm{~S}$ \\
\hline \multicolumn{3}{|l|}{ 2. Kepemimpinan Transformasional (X2) } \\
\hline Pengaruh Ideal (X2.1) & 3,61 & $\mathrm{~S}$ \\
\hline Motivasi Inspirasi (X2.2) & 3,86 & $\mathrm{~S}$ \\
\hline Stimulasi Intelektual (X2.3) & 4,01 & $\mathrm{~T}$ \\
\hline Konsiderasi Individu (X2.4) & 3,95 & $\mathrm{~S}$ \\
\hline Rerata Variabel & 3,56 & $\mathrm{~S}$ \\
\hline 3. Rerata Budaya Birokratik & 3,82 & $\mathrm{~S}$ \\
\hline 4. Rerata Budaya Inovatif & 3.93 & $\mathrm{~S}$ \\
\hline 5. Rerata Budaya Suportif & 4.00 & $\mathrm{~T}$ \\
\hline \multicolumn{3}{|l|}{ 6. Kinerja $(\mathrm{Y})$} \\
\hline Kuantitas pekerajaan (Y.1) & 3,91 & $\mathrm{~S}$ \\
\hline Kualitas pekerjan (Y.2) & 3,98 & $\mathrm{~S}$ \\
\hline Ketepatan waktu (Y.3) & 4,01 & $\mathrm{~T}$ \\
\hline Pengetahuan tentang pekerjaan (Y.4) & 3.88 & $\mathrm{~S}$ \\
\hline Keterampilan tentang pekerjaan (Y.5) & 4,06 & $\mathrm{~T}$ \\
\hline Kemampuan mengatur pekerjaan (Y.6) & 3,81 & $\mathrm{~S}$ \\
\hline Komunikasi (Y.8) & 3,09 & $\mathrm{~S}$ \\
\hline Rerata Variabel & 4,34 & $\mathrm{~T}$ \\
\hline
\end{tabular}

Kinerja karyawan dipersepsikan oleh para responden berada pada kategori tinggi dengan nilai rata-rata 4,43. Ini berarti bahwa kinerja karyawan yang menyangkut kauntitas pekerjaan, kualitas pekerjaan, ketepatan waktu, pengetahuan tentang pekerjaan, keterampilan tentang pekerjaan, kemampuan mengatur pekerjaan dan komunikasi di PT ASDP sudah baik.

\section{Pembuktian Hipotesis}

H1. Kepemimpinan transaksional dan transformasional secara parsial berpengaruh signifikan terhadap kineja karyawan PT ASDP Cabang Kupang. 
Hasil pengujian memperlihatkan bahwa secara parsial model kepemimpinan transaksional tidak berpengaruh signifikan terhadap kinerja karyawan PT ASDP Cabang Kupang ( $\mathrm{t}$ hitung $=1,206$ dengan nilai signifikansi $=0,321>0,05$ ). Sedangkan kepemimpinan transformasional berpengaruh signifikan ( $\mathrm{t}$ hitung $=2,022$ dengan nilai signifikansi $0,046<0,05)$.

H2. Kepemimpinan transaksional dan transformasional secara simultan berpengaruh signifikan terhadap kineja pegawai PT ASDP Indonesia Ferry Cabang Kupang.

Hasil pengujian memperlihatkan bahwa secara simultan model kepemimpinan transaksional dan kepemimpinan transformasional berpengaruh signifikan terhadap kinerja karyawan PT ASDP Cabang Kupang ( $\mathrm{F}$ hitung $=5,084$ dengan nilai signifikansi $=0,008<0,05)$.

H3. Budaya birokratik, inovatif, dan suportif secara parsial berpengaruh signifikan terhadap kinerja pegawai PT ASDP Indonesia Ferry Cabang Kupang.

Hasil pengujian memperlihatkan bahwa secara parsial budaya birokratik berpengaruh signifikan terhadap kinerja karyawan PT ASDP Cabang Kupang (t hitung = 2,343 dengan nilai signifikansi $=0,021<0,05)$. Demikian juga budaya suportif berpengaruh signifikan ( $\mathrm{t}$ hitung $=2,052$ dengan nilai signifikansi $0,043<0,05$ ) Sedangkan budaya inovatif tidak berpengaruh signifikan ( $\mathrm{t}$ hitung $=-0,201$ dengan nilai signifikansi $0,841>0,05)$.

H4. Budaya birokratik, inovatif, dan suportif secara simultan berpengaruh signifikan terhadap kinerja pegawai PT ASDP Indonesia Ferry Cabang Kupang.

Hasil pengujian memperlihatkan bahwa secara simultan budaya birokratik, inovatif, dan suportif berpengaruh signifikan terhadap kinerja karyawan PT ASDP Cabang Kupang ( $\mathrm{F}$ hitung $=3,545$ dengan nilai signifikansi $=0,018<0,05)$.

H5. Interaksi kepemimpinan transaksional dengan budaya inovatif berpengaruh signifikan terhadap kinerja pegawai PT ASDP Indonesia Ferry Cabang Kupang. 
Hasil pengujian memperlihatkan bahwa interaksi kepemimpinan transaksional dengan budaya inovatif tidak berpengaruh signifikan terhadap kinerja karyawan PT ASDP Cabang Kupang ( $\mathrm{t}$ hitung $=1,915$ dengan nilai signifikansi $=0,059>0,05$ ).

\section{H6. Interaksi kepemimpinan transaksional dengan budaya suportif beerpengaruh signifikan terhadap kinerja pegawai PT ASDP Indonesia Ferry Cabang Kupang.}

Hasil pengujian memperlihatkan bahwa interaksi kepemimpinan transaksional dengan budaya suportif tidak berpengaruh signifikan terhadap kinerja karyawan PT ASDP Cabang Kupang ( $\mathrm{t}$ hitung $=1,789$ dengan nilai signifikansi $=0,077>0,05$ ).

\section{H7. Interaksi kepemimpinan transformasional dengan budaya birokratik berpengaruh signifikan terhadap kinerja pegawai PT ASDP Indonesia Ferry Cabang Kupang.}

Hasil pengujian memperlihatkan bahwa interaksi kepemimpinan transformasional dengan budaya birokratik berpengaruh signifikan terhadap kinerja karyawan PT ASDP Cabang Kupang ( $\mathrm{t}$ hitung $=3,506$ dengan nilai signifikansi $=0,001<0,05$ ).

\section{Diskusi}

Model kepemimpinan transaksional, berdasarkan analisis tabel distribusi frekuansi, diterapkan pada kategori sedang, sementara dari analisis nilai rata-rata, model kepemimpinan ini lebih menonjol dirasakan oleh para pegawai karyawan pada PT ASDP Cabang Kupang daripada kepemimpinan transformasional. Temuan ini searah dengan pandangan Weber (Bass, 1985) bahwa kepemimpinan dalam organisasi cenderung transaksional. Meskipun kepemimpinan transaksional lebih menonjol dirasakan oleh para pegawai, namun hasil uji signifikansi menunjukkan bahwa model kepemimpinan ini tidak berpengaruh signifikan terhadap kinerja karyawan dengan besaran pengaruh hanya 0,317 dibandingkan kepemimpinan transformasional yang sebesar 0,329. Ini memberi kesan bahwa hasil penelitian ini tidak konsisten. Jika di telaah, temuan ini didukung oleh studi yang dilakukan oleh Trottier dkk (2008) yang menemukan bahwa pegawai federal menilai pemimpin mereka lebih tinggi dalam faktor kepemimpinan transaksional dibandingkan faktor transformasional, tetapi variasi kepuasan yang dijelaskan oleh kepemimpinan transaksional lebih rendah dibandingkan dengan kepemimpinan transformasional. Studi lain yang mendukung hasil penelitian ini adalah studi Pradeep dan 
Prahu (2011) yang menyimpulkan bahwa korelasi kepemimpinan transaksional dengan kinerja karyawan lebih rendah dari kepemimpinan transformasional. Kerry Webb (2007) juga menyimpulkan bahwa variasi motivasi kerja karyawan yang dijelaskan oleh kepemimpinan transaksional lebih rendah dari kepemimpinan transformasional.

Model kepemimpinan transformasional, sesuai analisis distribusi frekuensi, diterapkan pada kategori sedang (kadang-kadang) dan tidak terlalu menonjol dirasakan oleh para pegawai sebagaimana hasil analisis nilai rata-rata. Namun bila dikaitkan dengan analisis signifikansi, model kepemimpinan ini mempunyai pengaruh yang signifikan terhadap kinerja pegawai, dan mempunyai pengaruh yang lebih besar daripada kepemimpinan transaksional. Hasil penelitian ini sejalan dengan studi Paracha, dkk (2012), Pradeep dan Prabhu (2011), Rowold (2009), Voon, dkk, (2011), Riaz dan Haider (2010).

Temuan lain yang menarik adalah bahwa kepemimpinan transaksional dan transformasional diterapkan pada kategori sedang, yang berarti bahwa kedua model kepemimpinan ini diterapkan bergantian oleh pemimpin di PT ASDP secara seimbang. Kadang ia menggunakan model kepemimpinan transaksional tetapi kadang juga menggunakan model kepemimpinan transformasional. Temuan ini sejalan dengan pandangan Bass (1995) bahwa kepemimpinan transaksional dan kepemimpinan transformasional tidak berakhir pada sebuah kontinum tunggal, tetapi lebih merupakan pola kepemimpinan dimana seorang pemimpin memiliki kedua pola ini, hanya menggunakannya dalam kadar yang berbeda. Untuk kinerja yang tinggi kepemimpinan transformasional diperlukan untuk meningkatkan perilaku kepemimpinan transaksional. Jadi untuk meningkatkan kinerja pegawai di PT ASDP yang masih pada kategori sedang, diperlukan kepemimpinan transformsional.

Paparan temuan penelitian di atas, membawa implikasi teoritis dan praktis. Secara teoritis dapat dikatakan bahwa peran kepemimpinan transaksional sebagai penyumbang kinerja pegawai menunjukkan tendensi yang semakin kecil. Hal ini dapat dijadikan sebagai dasar untuk melakukan prediksi bahwa di masa yang akan datang, pandangan-pandangan yang mengatakan bahwa kepemimpinan organisasi yang cenderung transaksional akan gugur. Di masa mendatang kepemimpinan transformasional akan lebih menonjol dalam kepemimpinan di lingkungan organisasi. Untuk itu perlu penelitian lanjutan dalam substansi yang sama dan cakupan yang lebih luas dalam tingkatan organisasi yang lain agar dapat diperoleh gambaran yang lebih konprehensif tentang perkembangan kontribusi peran variabel model kepemimpinan terhadap kinerja karyawan. 
Secara praktis, temuan penelitian di atas merupakan signal bagi setiap pemimpin organisasi bahwa mulai saat ini dan ke depan harus lebih meningatkan kadar kepemimpinan transformasional. Suatu model kepemimpinan yang mampu memotivasi dan menginspirasi para pegawai dalam meningkatkan kinerja mereka. Dalam menentukan pemimpin sebuah organisasi, kemampuan dan kecakapan dalam mewujudkan kepemimpinan transformasional penting untuk dipertimbangkan.

Kecakapan sebagai pemimpin sebagai hal penting, karena suatu organisasi itu akan berhasil atau bahkan gagal sebagian besar ditentukan oleh faktor kepemiminan. Pemimpin selalu menjadi fokus evaluasi mengenai penyebab keberhasilan atau kegagalan suatu organisasi (Thoha, 2010). Selanjunya penekanan pada model kepemimpinan transformasional untuk ditonjolkan dalam kepemimpinan organisasi, karena model kepemimpinan ini mampu mendorong peningkatan kinerja pegawai sebagaimana hasil kajian berbebagai peneliti yang sudah dipaparkan sebelumnya. Di sisi lain model kepemimpinan transaksional lebih berorientasi pada politik kekuasaan, mengembangkan sistem nepotisme, tidak ada pemberdayaan karyawan, dan lain-lain yang berujung pada rendahnya kinerja aparat birokrasi (Anwaruddin, 2006).

Analisis melalui table frekuensi menunjukkan bahwa budaya birokratik, dan budaya inovatif cukup menggambarkan PT ASDP Cabang Kupang, sedangkan budaya suportif adalah budaya yang paling menggambarkan PT ASDP Cabang Kupang. Di sisi lain hasil uji signifikansi menunjukkan bahwa budaya birokratik dan budaya suportif mempunyai pengaruh yang signifikan terhadap kinerja karyawan, sedangkan budaya inovatif tidak berpengaruh signifikan. Hasil studi ini berbeda dengan Ababaneh (2010) yang menemukan bahwa budaya biroktarik, inovatif dan suportif mempunyai pengaruh yang positif dan signifikan terhadap perbaikan kualitas praktek Rumah Sakit Umum Jordania. Juga studi Studi Odom, dkk (1990) yang menemukan bahwa budaya birokratik paling dominan terdapat pada industri transportasi, diikuti sedikit budaya inovatif, tetapi kurang memiliki budaya suportif.

Analisis lebih lanjut memperlihatkan bahwa interkasi antara kepemimpinan transaksional dan budaya inovatif tidak berpengaruh signifikan terhadap kinerja karyawan PT ASDP Cabang Kupang. Hal yang sama terjadi pada interaksi antara kepemimpinan transaksional dengan budaya suportif, dimana tidak berpengaruh signifikan terhadap kinerja karyawan. Di sisi lain interkasi antara kepemimpinan transformasional dengan budaya birokratik mempunyai pengaruh yang signifikan terhadap kinerja karyawan. 
Hasil kajian ini mempunyai implikasi bahwa jika suatu organisasi mempunyai budaya birokratik dan inovatif maka sebaikanya pemimpinya tidak menerapkan kepemimpinan transaksional. Tetapi jika memepunyai budaya suportif maka, lebih cocok menerapkan kepemimpinan transformasional.

\section{SIMPULAN}

1. Model kepemimpinan transaksional tidak berpengaruh signifikan terhadap kierja karyawan di PT ASDP Cabang Kupang.

2. Model kepemimpinan transformasional berpengaruh signifikan terhadap kinerja karyawan di PT ASDP Cabang Kupang

3. Model kepemimpinan transaksional dan transformasional secara bersama-sama berpengaruh signifikan terhadap kierja karyawan di PT ASDP Cabang Kupang

4. Model kepemimpinan transformasional mempunyai pengaruh lebih besar terhadap kinerja karyawan PT ASDP Cabang Kupang

5. Budaya birokratik berpengaruh signifikan terhadap kinerja karyawan PT ASDP Cabang Kupang

6. Budaya inovatif tidak berpengaruh signifikan terhadap kinerja karyawan PT ASDP Cabang Kupang.

7. Budaya suportif berpengaruh signifikan terhadap kinerja karyawan PT ASDP Cabang Kupang.

8. Budaya birokratik, inovatif dan suportif secara simultan berpengaruh signifikan terhadap kinerja karyawan PT ASDP Cabang Kupang

9. Interaksi kepemimpinan transaksional dengan budaya inovatif tidak berpengaruh signifikan terhadap kinerja karyawan PT ASDP Cabang Kupang

10. Interaksi kepemimpinan transaksional dengan budaya suportif tidak berpengaruh signifikan terhadap kinerja karyawan PT ASDP Cabang Kupang.

11. Interaksi kepemimpinan transformasional dengan budaya birokratik berpengaruh signifikan terhadap kinerja karyawan PT ASDP Cabang Kupang.

\section{DAFTAR PUSTAKA}

Ababaneh Ismail Raed, 2010, The Role of Organizational Culture on Practising Quality Improvement in Jordanian Public Hospitals, Leadership in Health Sevices Vol 23 No.3, 2010. 
Axtell, C.M.,dkk, 2000, Shop floor innovation : facilitating the suggestion and implementation of ideas, Journal of Occupational \& Organizational Psycology, Vol 73, pp 265-285.

Avolio, B. J., Zhu, W., Koh, W. L., \& Bhatia, P., 2004, Transformasional Leadership and Organizational Comitment; Mediating role of psycological empowerment and moderating role of structural distance, Organizational Behavior, 25, 951-968.

Bass, B. M., 1985, Leadership and Performance Beyond Expectation. New York: Free Press.

Bass, B. M., 1990, Bass \& Stogdill's handbook of leadership (3rd Ed) New York : The Free Press.

Bass, B. M. \& Riggio, R. E., 2006, Transformational Leadership (2ed) Mahwah, NJ : Lawrence Erlbaum Assosiates Inc.

Baldoni, J., 2005, Great Motivation Secret of Great Leaders. McGraw Hill Professional

Bernandin H. John \& Joyce E.A. Russel, 1993, Human Resource Management, MacGrawHill, Inc. Singapore.

Burns, J. M., 1978, Leadership, New York : Harper \& Row.

Campbell, J. P., McCloy, R. A., Oppler, S. H., \& Sager, C. E., 1993. A theory of performance. In E. Schmitt, W. C. Borman, \& Associates (Eds.), Personnel selection in organizations (pp. 35-70). San Francisco: Jossey-Bass.

Coberg, C. S. \& Cusmir, L. H., 1987, Orgnizational Culture Relationships with Creativity and Other Job-Related Variabels, Journal of Business Research 15, 397-409.

Dwiyanto, Agus, dkk, 2002, Reformasi Birokrasi Publik di Indonesia, Yogyakarta, Pusat tudi Kependudukan dan Kebijakan UGM.

Dessler Gary, 1997, Manajemen Sumber Daya Manusia, Jili 1 dan 2, Terjemahan Triana Iskandarsyah, PT Prenhallindo, Jakarta.

Furtwengler Dale, 2002, Penilaian Kinerja, Andi Yogyakarta.

Helriegel, D. \& Slocum, J., 2006, Organizational Behavior (11th Ed) Mason OH South Western.

Higgins Michael, 1984, Advantage and Limitation of ROI as Measure of Corporate Performance. Terjemahan Bambang Triono, PT Gramedia Jakarta.

Krishman, V. R., 2004, Impact of transformational leadership on followers' influence strategies, Leadership and Organization Development Journal, 25 (1), 58-72. 
Kinerja Kabupaten/Kota di kawasan Timur Indonesia mengecewakan, Biak Rasine, 25 April 2011.

Kilmann, 1996, Beyond the Quicks Fix, Managing Five Tracks to Organisasional Success, Litton Educational Publishing, USA.

Kristof, K., 1996, Person-organization fit : an integrative review of its conceptualizations, measurement and implications, Personal Psychology, Vol. 49 No. 1.

Kaufman, R., 2002, Prometheon Builds a Company Culture That Serves, Sizzles \& Succeeds.

Lok Peter, 2011, The Mediating Role of Organizational Subculters in Healt Care Organizations, Journal of Health Organization and Management, Vol 25 No. 5, pp 506-525.

Martin, J., 1992, Cultur in organizations : Three Perspectives, Oxford University Press New York NY.

Mondy, Wayne R Siharplin Arthur \& Flipo Edwin B, 1995, Management : Concepts and Practices, Fourth Edition, Boston Allyn and Bacon, Inc.

Mitchel, T.R., Lason, J.R., 1987, People in organization, 3rd ed. New York: Mc GrawHill.

Odom Y Randall, dkk, 1990, Organizational Cultures, Commitment, Satisfaction and Cohesion, Public Productivity \& Management Review, Vol 14 No 2, pp 157-169.

O'Reilly, C.A., 1989, Corporation, culture, and commitment : motivation and social control in organization, California Management Review, Vol 31 No 4.

PNS berkeliaran diberi sangsi, Pos Kupang, 25 Oktober 2012.

Pfeffer J. (1996), Competitive Advantage Through People, Harvard Business School Press.

Parry, K. W., 1998, Grounded Theory and Social Process : A new direction for leadership research, Leadership Quarterly, 9 85-105.

Paracha, M. Umer dkk., 2012.Impact of Leadership Style (Transformational \& Transactional Leadership) On Employee Performance \& Mediating Role of Job Satisfaction Study of Private School (Educator) In Pakistan, Global Journal of Management and Business Research Volume 12 Issue 4 Version 1.0 March.

Pradeep Durga Devi dan Prabhu N.R.V., 2011. The Relationship between Effective Ledership and Employee Performance, IPCSIT vol 20 (2011) IACSIT Press, Songapore.

Ravianto J, 1986, Produktivitas dan Seni Usaha, Lembaga Sarana Informasi Usaha dan Produktivitas Jakarta. 
Rivai Veithzal \& Sagala Jauvani Ella, 2009, Manajemen Sumber Daya Manusia Untuk Perusahaan Dari Teori ke Praktek, Edisi Kedua, Rajawali Pers.

Sarmiento, R., Beale, J. and Knowles, G., 2007, Determinan of performance amongst shop-floor employees : a preliminary investigation, Management Research News, Vol 30 No 12, pp 915-927.

Smith, G.P., 2002, The New Leader : Bringing Creativity and innovation to the workplace. Chart your course, Conyers, GA.

Simic, I., 1998, Transformational Leadership : The key to successful management. Organizational Change, 1 (6), 49-55.

Suryanto, dkk., 2008, Kajian Pengukuran dan Evaluasi Kinerja Manajemen PNS di Daerah,Pusat Kajian Kinerja Otonomi Daerah J1. Veteran no 10 Jakarta.

Sugiono, 2004, Metode Penelitian Bisnis, CV Alfabeta Bandung.

Trottier Tracey, dkk., 2008. Examining the Nature and Significance of Leadership in Government Organizations, Essay on Leadership in Organization, Public Administration Review, March/April 2008.

Tichy, N. M, \& Devanna, M. A., 1986, The Transformsional leader, New york : Wiley.

Webb Kerry, 2007, Motivating Peak Performance : Leadership Behavior That Stimulate Employee Motivation and Performance, Christian Higher Education, 6 : 53-71.

Wallach E, 1983, Individuals and Organization : the culture match, Training and Development Journal, Vol 12, pp 28-36. 